\title{
Electrokinetic and potentiometric insight into malonate arrangement at hematite/water interface
}

\author{
KAROLINA KEDRA-KROLIK ${ }^{1}$, TAJANA BEGOVIĆ ${ }^{2}$, \\ MARZENA PRUS $^{3}$, DANIJEL NAMIESNIK ${ }^{2}$ AND PIOTR \\ ZARZYCKI $^{4}$ \\ ${ }^{1}$ Institute of Physical Chemistry PAS \\ ${ }^{2}$ Department of Chemistry, Faculty of Science, University of \\ Zagreb \\ ${ }^{3}$ Institute of Physical Chemistry Polish Academy of Science \\ ${ }^{4}$ Energy Geosciences Division, Lawrence Berkeley National \\ Laboratory, Berkeley, CA \\ Presenting Author: kkedrakrolik@ichf.edu.pl
}

The aliphatic low-molecular-weight carboxylic acids, released by plants roots or microbes to the rizosphere, improves the solubility of nutritient cations from soil minerals and rock fragments, and increases their bioavailability [1]. The incorporating of iron in nature and its bio-availability is controlled by adsorption-desorption processes. To understand the role of carboxylic acids in hematite dissolution and reactivity, we need to gain an insight into the nature of $\mathrm{pH}$-dependent iron oxide surface chemistry [2].

By combining measurements of surface and diffuse potential at hematite/water interface with the potentiometric titration of suspension we were able to precisely describe the electrical double layer properties of the hematite/malonic solution interface. We observed that malonate adsorbs in a broad $\mathrm{pH}$ range from 3 to 8.3 , however, the mode of coordination depends on actual $\mathrm{pH}$ value. We distinguished two different types of malonate complexation to the hematite surface: as innerspherical complexes at $\mathrm{pH}$ below 4 , and as outer-spherical complexes above $\mathrm{pH}$ 5. The transition from the inner to the outer sphere geometries is smooth, suggesting that both types of complexes geometries exist simultaneously, but with a ratio depending on the $\mathrm{pH}$. Our findings are relevant for understanding how organic matter interacts with minerals, a key phenomenon in the chemical weathering processes.

[1] Strobel B.W. (2001) Geoderma, 99, 169-198

[2] Duckworth O.W. et al. (2001) Geochim. Cosmochim. Acta. 65 4289-4301 